\title{
Sistema de Saúde e Trabalho: desafios para a Enfermagem no Brasil
}

\author{
Health and Work System: challenges for the Nursing in Brazil
}

Manoel Carlos Neri da Silva (https://orcid.org/0000-0002-3923-7473) ${ }^{1}$

Maria Helena Machado (https://orcid.org/0000-0002-5209-2424) ${ }^{2}$

${ }^{1}$ Conselho Federal de Enfermagem. Quadra CLN 304 Bloco E, Asa Norte. 70736-550 Brasília DF Brasil.

nericoren@gmail.com

${ }^{2}$ Escola Nacional de Saúde Pública Sérgio Arouca, Fiocruz. Rio de Janeiro RJ Brasil.

\begin{abstract}
This paper discusses the importance of the Nursing to the Unified Health System, considering its presence in all organizational health structures, in the 27 units of the Federation and all municipalities of the country, essential, therefore, for the provision of high-quality health care. Nevertheless, the profession faces many challenges, both in the field of education and in the job market, that must be addressed, aiming at the valorization of these professionals who, despite all the difficulties they are subjected to, are committed to the health of the Brazilian population.

Key words Nursing, Job market, Brazilian Nursing Profile
\end{abstract}

Resumo $O$ artigo debate a importância da Enfermagem para o Sistema Único de Saúde, considerando a mesma estar presente em todas as estruturas organizacionais de saúde, nas 27 unidades da Federação e em todos os municípios do país, essencial, portanto, para a prestação de uma assistência de qualidade. Apesar disso, a profissão enfrenta muitos desafios, quer no campo da formação e do mercado de trabalho, que necessitam ser enfrentados, visando a valorização desses profissionais que apesar de todas as dificuldades a que estão submetidos, são comprometidos com a saúde da população brasileira.

Palavras-chave Enfermagem, Mercado de trabatho, Perfil da Enfermagem no Brasil 


\section{Introdução}

Falar sobre o Sistema Único de Saúde (SUS) é trazer à tona o processo de instituição do maior e mais eficiente sistema gratuito de saúde do mundo, criado para atender a todos os brasileiros e brasileiras, sem distinção, e assim reconhecido pela Organização Mundial de Saúde (OMS).

Ao ser criado como uma política pública, ter entrado na pauta da política dos anos 1980 e finalmente ser inserido na Constituição Federal de 1988, com a instituição do SUS pela Lei $\mathrm{n}^{\mathrm{o}} 8.080 / 90^{1}$, o Brasil deu um passo decisivo que mudou o modelo de atendimento à saúde, antes seletivo e centralizado.

Seus princípios de equidade, universalidade, integralidade, descentralização e participação social trouxeram a possibilidade a todos, mas principalmente aos mais pobres, aos desamparados e sem empregos de também terem o acesso à saúde. O SUS é inclusivo e está em todas as áreas da Saúde - realiza os procedimentos mais simples e os mais complexos. Hoje, 30 anos após sua criação, o SUS presta atendimento a mais de 11 milhões de pessoas por dia e realiza cerca de 127 procedimentos por segundo.

Entrelaçada à existência do SUS está a Enfermagem. Um contingente muito expressivo, representando mais da metade de todos os profissionais de saúde em atuação no Brasil. Não é possível pensar no funcionamento desse Sistema sem o trabalho dos enfermeiros, técnicos e auxiliares de Enfermagem presentes em cada município brasileiro, em cada unidade e instituição de saúde.

As vitórias e desafios do SUS também estão interligados aos da Enfermagem brasileira. Se o SUS é subfinanciado desde sua criação, os profissionais de Enfermagem sofrem com a falta de um piso nacional salarial, o que resulta em salários baixíssimos, chegando um profissional, em determinadas regiões do País, a recorrer à outras atividades fora da saúde, como forma de complementação de seu rendimento mensal.

O SUS sobreviveu às mudanças de governo, estando associado à redução da mortalidade infantil, ao aumento da expectativa de vida e à melhoria generalizada dos principais indicadores de Saúde no Brasil nas últimas três décadas. É uma conquista da população que não pode ser desprezada. Ele aumentou o acesso dos brasileiros à saúde como não se pensava ser possível acontecer 30 anos atrás. Hoje, sete em cada dez brasileiros dependem exclusivamente do Sistema Público de Saúde. Isso equivale a $75 \%$ de brasileiros. A Aten- ção Primária, porta de entrada à Saúde, alcança hoje 50\% dos usuários. A Organização Mundial de Saúde afirma, com base em evidências internacionais, que sistemas de Saúde baseados em uma Atenção Primária à Saúde forte apresentam melhores resultados, menores custos e maior qualidade de atendimento.

Na opinião de Santos²:

os inquestionáveis avanços do SUS a favor das necessidades e direitos da população constitui patamar inabdicável de realizações, conhecimentos e práticas. No âmbito da Atenção Básica em Saúde $(A B)$, aumentou a integração das ações promotoras, protetoras e recuperadoras da saúde, apoiadas em diagnósticos epidemiológicos, sociais, formação profissional e processos de trabalho em equipe. Foi constatada na prática que a resolutividade pode chegar a $80 \% / 90 \%$ de atendimento às necessidades de saúde ${ }^{2}$ (p. 1731).

\section{A Enfermagem e o SUS}

A Enfermagem é uma profissão essencial e considerada nuclear na estrutura das profissões de saúde, no Brasil e no mundo. É uma categoria profissional que se organiza de forma peculiar, tendo na sua estrutura interna 3 categorias: Enfermeiro, Técnico de Enfermagem e Auxiliar de Enfermagem.

Constituída por um contingente de mais de 2 milhões de profissionais, presente nos $5.570 \mathrm{mu}$ nicípios, nas 27 unidades da Federação. Presente, também, em todas as estruturas organizacionais do sistema de saúde brasileiro: hospitais, ambulatórios, centros de saúde, UBS, UPAS, SAMUs, ESF, etc.

Por ser uma profissão que atua nas várias dimensões da saúde: na assistência (muito forte), na saúde pública, na prevenção e promoção da saúde, presente em todas as fases de nossas vidas: do nascer ao morrer, confere a ela a noção sociológica, de essencialidade no âmbito das profissões.

Da mesma forma, a multifuncionalidade, característica da formação em Enfermagem, possibilitou a expansão dos espaços de atuação dos profissionais, que estão atuando em todos os processos e procedimentos do SUS, inclusive na gestão, coordenação de Programas como o Estratégia Saúde da Família, gerenciamento e a assistência. A Enfermagem é ponto nevrálgico de qualquer sistema de Saúde - sem ela não há como seguir com o trabalho.

Ao mesmo tempo em que o SUS e o processo de descentralização de ações e serviços de saúde 
foi ganhando amplitude, especialmente, para estados e municípios, foi demandando uma força de trabalho ainda maior e mais especializada para cada área de atuação. A Enfermagem se inseriu e ao longo dessa história, vem contribuindo, não só na implantação e implementação das diversas políticas de saúde (Estratégia Saúde da Família, SAMU, imunizações, controle de doenças endêmicas, entre outras), mas de estar diuturnamente para manutenção desse sistema, desde os grandes centros até os locais mais remotos do país.

O Brasil é referência para qualquer país que queira aprender sobre a Atenção Primária, afirmou o inglês Thomas Hone, pesquisador no Imperial College of London, que estuda sistemas universais de saúde. A Enfermagem tem forte atuação na atenção primária, e na emergência das Práticas Avançadas de Enfermagem, oferece uma perspectiva de maior resolutividade, eficácia e eficiência.

\section{A Formação}

Adequar a formação às necessidades do Sistema Único de Saúde e ao mesmo tempo ordenar a formação, combatendo os cursos de baixa qualidade, é um outro grande desafio da profissão. A equipe de Enfermagem é um contingente jovem, representando $61,7 \%$ têm até 40 anos de idade.

No estudo realizado por Machado $^{3}$ sobre a Enfermagem é possível destacar alguns pontos referentes à educação: primeiro, a iniciativa privada domina a formação destes profissionais, o que significa dizer que 57,4\% dos enfermeiros e $72 \%$ dos técnicos e auxiliares são oriundos de instituições de ensino privadas; segundo, há uma clara hegemonia do Sudeste no que tange a formação profissional (50\%); terceiro, $1 / 3$ dos enfermeiros foi, anteriormente, técnico ou auxiliar de enfermagem. Quanto a qualificação de Pós-Formação os dados remetem a um quadro bastante díspar na equipe: entre os enfermeiros, $4,7 \%$ são doutores, 14,5\% são mestres e 72,8\% têm Especialização; já entre os auxiliares e técnicos apenas 23\% têm Especialização e 45,8\% fizeram alguma atualização no decorrer de sua vida profissional. E $60 \%$ informam que fizeram nenhuma qualificação nos últimos 12 meses.

Contudo, o desejo de se qualificar é um anseio do profissional de Enfermagem brasileiro, que busca melhorar sua posição no mercado de trabalho - 80,1\% dos enfermeiros reportam ter feito cursos de pós-graduação, sendo a maioria (72,8\%) na modalidade de Especialização, segundo dados da Pesquisa Perfil da Enfermagem no Brasil ${ }^{3}$. A maioria, 78,1\% dos trabalhadores de nível médio (técnicos e auxiliares), deseja cursar graduação e muitos já apresentam escolaridade acima da exigida para o desempenho de suas atribuições, com 22,8\% reportando nível superior incompleto e $11,5 \%$ tendo concluído curso de graduação (Quadro 1).

Entretanto, ainda é baixa a taxa de profissionais com pós-graduação na modalidade Residência e elevado em Especializações, muitas vezes desconectados com o que realmente precisa o Sistema de Saúde do País.

Segundo Machado ${ }^{3}$ :

três tendências podem-se perceber no perfil da formação profissional: a) tendência à privatização, com hegemonia da iniciativa privada tanto na formação básica como na oferta de cursos de Especialização, Atualização e Aperfeiçoamento, ou seja, na modalidade Lato Sensu; b) tendência a perda da importância da modalidade integral dos cursos de formação profissional (para enfermeiros e auxiliares e técnicos); c) e o crescente aumento da escolarização dos trabalhadores, ou seja, 1/3 de todo o contingente auxiliar e técnico tem curso superior completo ou está cursando ${ }^{3}$ (p. 713).

A Enfermagem está se tornando uma profissão universitária.

Por outro lado, registra-se uma proliferação de escolas privadas no ensino técnico e superior, sem a observância da qualidade do ensino. Segundo dados do Cofen ${ }^{4}$, em 2018 foram registrados 149.425 novos profissionais nos Conselhos de Enfermagem, sendo: 36.359 enfermeiros, 24 obstetrizes, 94.676 técnicos de enfermagem e 18.366 auxiliares de enfermagem egressos das 6.719 escolas existentes no país (819 cursos de graduação em enfermagem, 3.877 escolas de formação técnica e 2.023 cursos de auxiliar de enfermagem), sem considerar os polos de ensino a distância ${ }^{4}$.

Esse crescimento dos cursos acompanhou a tendência de crescimento de todas as áreas, resultado de um processo de expansão da educação para criar oportunidades educacionais, muitas vezes sem seguir um critério ordenado.

Ademais, com o advento do ensino a distância $(\mathrm{EaD})$ na formação de enfermeiros e a implantação de polos a distância, majoritariamente em municípios de pequeno e médio porte sem a infraestrutura necessária, além da expansão do número de vagas para formação de enfermeiros de forma dramática, contribui ainda mais para a piora da qualidade da formação. Aliado a isso, os municípios não têm capacidade de absorver esse contingente, um descompasso entre oferta 
Quadro 1. Caracterização da profissão de Enfermagem - Brasil.

\begin{tabular}{|c|c|c|}
\hline \multicolumn{2}{|l|}{ Descrição } & $(\%)$ \\
\hline \multirow[t]{2}{*}{ Categoria Profissional } & Enfermeiro & 23,0 \\
\hline & Técnico e Auxiliar de Enfermagem & 77,0 \\
\hline \multirow[t]{2}{*}{ Sexo (Equipe de Enfermagem) } & Masculino & 14,4 \\
\hline & Feminino & 85,1 \\
\hline \multirow[t]{2}{*}{ Faixa Etária (Equipe de Enfermagem) } & Até 40 anos & 61,7 \\
\hline & Mais de 61 anos & 2,1 \\
\hline \multirow[t]{2}{*}{ Local de Residência (Equipe de Enfermagem) } & Capital & 56,8 \\
\hline & Interior & 40,9 \\
\hline \multirow[t]{6}{*}{ Natureza da Instituição Formadora } & \multicolumn{2}{|l|}{ Enfermeiros } \\
\hline & Pública & 35,6 \\
\hline & Privada & 57,4 \\
\hline & \multicolumn{2}{|c|}{ Auxiliares e Técnicos de Enfermagem } \\
\hline & Pública & 16,0 \\
\hline & Privada & 72,0 \\
\hline $\begin{array}{l}\text { Enfermeiros com curso de Técnico ou Auxiliar de } \\
\text { Enfermagem antes da Graduação }\end{array}$ & Sim & 31,4 \\
\hline \multirow[t]{2}{*}{ Modalidades de Pós-Graduação dos Enfermeiros } & Pós-Graduação & 80,1 \\
\hline & . Especialização & 72,8 \\
\hline \multirow{3}{*}{$\begin{array}{l}\text { Nível de Escolaridade dos Auxiliares e Técnicos de } \\
\text { Enfermagem }\end{array}$} & Nível superior incompleto & 22,8 \\
\hline & Nível superior completo & 11,5 \\
\hline & . Pretensão em continuar os estudos & 78,1 \\
\hline $\begin{array}{l}\text { Aprimoramento Profissional nos últimos } 12 \text { meses dos } \\
\text { Auxiliares e Técnicos de Enfermagem }\end{array}$ & Sim & 47,5 \\
\hline \multirow[t]{3}{*}{ Atividade Profissional no setor (Equipe de Enfermagem) } & Público & 58,9 \\
\hline & Privado & 31,6 \\
\hline & Filantrópico & 15,4 \\
\hline \multirow[t]{9}{*}{ Rendimento Mensal (Equipe de Enfermagem) } & \multicolumn{2}{|l|}{ Setor Público } \\
\hline & Até 1.000 reais & 14,4 \\
\hline & Até 3.000 reais & 62,5 \\
\hline & \multicolumn{2}{|l|}{ Setor Privado } \\
\hline & Até 1.000 reais & 22,1 \\
\hline & Até 3.000 reais & 68,2 \\
\hline & \multicolumn{2}{|l|}{$\begin{array}{r}\text { Setor Filantrópico } \\
\end{array}$} \\
\hline & Até 1.000 reais & 23,7 \\
\hline & Até 3.000 reais & 70,1 \\
\hline Atividade Desgastante (Equipe de Enfermagem) & Sim & 65,9 \\
\hline $\begin{array}{l}\text { Necessidade de Atendimento Médico nos últimos } 12 \text { meses } \\
\text { (Equipe de Enfermagem) }\end{array}$ & Sim & 56,1 \\
\hline $\begin{array}{l}\text { Acidente de Trabalho nos últimos } 12 \text { meses - público, } \\
\text { privado e filantrópico (Equipe de Enfermagem) }\end{array}$ & Média & 10,8 \\
\hline $\begin{array}{l}\text { Assistência da Instituição em caso de doença (Equipe de } \\
\text { Enfermagem) }\end{array}$ & Sim & 40,6 \\
\hline Prática regular de esporte (Equipe de Enfermagem) & Sim & 33,8 \\
\hline $\begin{array}{l}\text { Proteção no ambiente de trabalho contra violência (Equipe } \\
\text { de Enfermagem) }\end{array}$ & Sim & 29,0 \\
\hline $\begin{array}{l}\text { Tratamento com Cordialidade e Respeito (Equipe de } \\
\text { Enfermagem) }\end{array}$ & Pela população usuária & 47,2 \\
\hline $\begin{array}{l}\text { Violência no Ambiente de Trabalho (Equipe de } \\
\text { Enfermagem) }\end{array}$ & Sim & 19,7 \\
\hline $\begin{array}{l}\text { Infraestrutura de descanso - público, privado e filantrópico } \\
\text { (Equipe de Enfermagem) }\end{array}$ & Média & 45,4 \\
\hline
\end{tabular}

Fonte: Adaptado do Quadro Resumo de Machado ${ }^{3}$. 
de cursos e a ausência de políticas públicas para a inclusão dos egressos no mercado de trabalho.

\section{O Mercado de Trabalho}

O mercado de trabalho da Enfermagem, segundo dados da pesquisa apontam para uma composição bastante desigual, registrada em todo o País, ou seja, 77\% são técnicos e auxiliares, enquanto somente $23 \%$ são enfermeiros. Há uma concentração destes na Região Sudeste, enquanto o Norte e o Nordeste sofrem com a carência desses profissionais. Da mesma forma, é possível visualizar uma clara concentração também nos grandes centros urbanos, em especial, nas capitais tendo mais da metade de todo o contingente morando e trabalhando ${ }^{3}$.

Importante saber onde atuam e como está esse imenso contingente da saúde. Buscando os dados da Pesquisa Perfil da Enfermagem no Bra$\mathrm{sil}^{3}$, pode-se ter a seguinte radiografia da empregabilidade da categoria (Quadro 1).

Atuando no setor público somam 58,9\% de toda a Força de Trabalho, se tornando o maior e mais importante empregador da Enfermagem. No entanto, os dados não são animadores, uma vez que destes, metade estão em situação de precarização do trabalho, 62,5\% têm salários de até 3 mil reais e $14,4 \%$ estão na condição de subsalários (igual ou inferior a mil reais).

O setor privado também se mostra um grande empregador, respondendo por $1 / 3$ do contingente, ou seja, $31,6 \%$ atuam no setor privado. Por outro lado, $40 \%$ estão na condição de precarização do trabalho, 68,2\% têm salários de até $3 \mathrm{mil}$ reais e $22,1 \%$ recebem subsalários (igual ou inferior a mil reais).

Já outro setor de expressão nos estados e no âmbito do SUS é o filantrópico, que congrega $15,4 \%$ desse contingente, $40 \%$ estão em situação de precarização do trabalho, 70,1\% têm salário igual ou inferior a 3 mil reais e $23,7 \%$ recebem subsalários (igual ou inferior a mil reais).

O subfinanciamento do SUS, agravado pela Emenda 95/2016, que estabelece teto dos gastos e congelamento dos investimentos em saúde, educação e assistência social pelos próximos 20 anos, também vai afetar, a médio prazo, a demanda e os salários dos profissionais de Enfermagem.

Ademais, a Pesquisa Perfil da Enfermagem no Brasil aponta para um fenômeno decorrente do desequilíbrio entre oferta e demanda de mão de obra, no qual, por razões do boom de escolas de Enfermagem e, consequentemente da oferta desenfreada de novos profissionais no mercado de trabalho, como citado acima, leva ao desemprego aberto e estrutural.

Na opinião de Machado e Ximenes Neto ${ }^{5}$ :

Se por um lado podemos nos orgulhar do gigantismo do SUS em termos de capacidade instalada - número de estabelecimentos de saúde (ambulatoriais e hospitalares), leitos e empregos de saúde, com mais de 3,5 milhões de trabalhadores atuando em equipes multiprofissionais, qualificadas e especializadas, por outro, é fato também que esse setor se mantém crescendo e gerando novos postos de trabalho. Contudo, há problemas estruturais que ainda persistem, especialmente na gestão do trabalho, tais como: desequilíbrio entre oferta e demanda, escassez de profissionais no interior do país, precarização do trabalho, terceirização dos serviços de saúde e, consequentemente, da mão de obra especializada (médicos, enfermeiros, técnicos em geral, dentre outros). O trabalho precário é uma situação que atinge significativo contingente da saúde ${ }^{5}$ (p. 1977).

Contraditoriamente, observa-se outro fenômeno: a escassez de enfermeiros em todo o território nacional, especialmente nos interiores do País, ou seja, 56,8\% vivem e trabalham nas capitais, deixando os interiores com déficit de profissionais para o atendimento à população. É falsa a ideia que há abundância de enfermeiros em contrapartida, com a escassez na assistência à saúde da população no País. Tudo isso leva a um denominador comum: baixo crescimento na empregabilidade entre os enfermeiros retratada em toda a estrutura do SUS, seja na esfera pública, privada ou filantrópica, no qual é adotada a política de manter percentuais baixos de enfermeiros na composição da equipe de Enfermagem, gerando clara sobrecarga para os enfermeiros.

Para Machado ${ }^{3}$ :

Três tendências podem-se perceber no perfil do mercado de trabalho: a) tendência à uma FT mais jovem, recém ingressa no mercado de trabalho, ainda em processo de qualificação profissional; $b$ ) tendência ao aumento do desemprego, hoje na ordem dos $10 \%$, afetando mais intensamente aqueles jovens acima citados; c) e o crescente aumento da busca de oportunidades e atividades fora da enfermagem complementando a renda mensal ${ }^{3}$ (p. 715).

É fato que o trabalho na saúde gera desgaste, stress e adoecimento. A pesquisa Perfil da Enfermagem no Brasil procurou saber como estão os enfermeiros, técnicos e auxiliares de Enfermagem. Os dados mostram também que 65,9\% declaram desgaste profissional. $\mathrm{O}$ aumento é crescente, gerando depressão, obesidade, extremo cansaço, sentimento de desvalorização, com índices alarmantes de licenças médicas. 
Reforçando a afirmação de que a Enfermagem no Brasil está com sinais de esgotamento é o fato de $56,1 \%$ terem adoecido nos últimos 12 meses precisando de atendimento médico; os altos índices de acidente de trabalho, ou seja, 10\% (média) seja no setor público, privado ou filantrópico, o que significa dizer que mais de $180 \mathrm{mil}$ profissionais se acidentaram nos últimos 12 meses, segundo dados da pesquisa. Informam também que se sentem desassistidos, ou seja, quando adoecem, apenas $40,6 \%$ deles são atendidos em seu próprio trabalho, muitas vezes morrem na rotina do trabalho. O sedentarismo é outro fator desencadeador de doenças e no caso da Enfermagem, $66,2 \%$ estão sedentários, não praticam esportes regularmente, alegando cansaço, falta de tempo e oportunidade.

Por fim, é preciso mencionar a avaliação da Enfermagem sobre o ambiente de trabalho que esses 2 milhões de trabalhadores estão atuando. Os dados da pesquisa mostram que $71 \%$ se sentem desprotegidos no seu ambiente de trabalho por conta da violência instalada em boa parte dos hospitais, ambulatórios, postos de saúde, etc. em todo o País. Uma parte significativa $(52,8 \%)$ declara ser maltratada e desrespeitada pela população usuária, especialmente pelos familiares dos pacientes e 19,7\% já sofreram violência física, psicológica ou institucional.

Também não há mínimo de conforto nos locais de trabalho para aqueles que fazem plantões e necessitam de um momento de descanso, ou seja, menos da metade informa que há infraestrutura de descanso onde trabalha.

\section{Notas finais}

O mais recente desafio da Enfermagem trata-se da Reforma da Previdência, que vai afetar demasiadamente os profissionais de Enfermagem. Uma categoria majoritariamente feminina $(85 \%)$ e exposta a intenso desgaste físico e psicológico, além dos riscos biológicos. A Pesquisa Perfil da Enfermagem no Brasil indica que as exigências inerentes à profissão se refletem no mercado de trabalho: somente $2,1 \%$ dos profissionais em atuação no Brasil têm mais de 60 anos. Seis em cada dez profissionais têm menos de 40 anos. É imperativo, portanto, adequar a proposta à realidade de trabalho específica da Enfermagem.

Os profissionais da Enfermagem parecem invisíveis aos olhos dos políticos, dos empresários e dirigentes das instituições de saúde e, muitas vezes, da população. São invisíveis até para eles próprios, que têm a autoestima baixa. A maior área da saúde, com mais de dois milhões de brasileiros, não consegue ver aprovadas as reivindicações imprescindíveis para a melhoria de seu trabalho, de sua saúde e de toda a população do País. É curioso como não percebem ou fingem não perceber esse gargalo na saúde.

Mesmo com o avanço tecnológico e inovador na área da saúde, o ser humano ainda é o mais importante insumo. É o olhar, o toque, a presença, o atendimento preciso, a técnica e a fidelidade do profissional de Enfermagem que, mesmo tendo todas as dificuldades, está à frente dos principais procedimentos. $\mathrm{Na}$ entrada e em todos os estágios e processos de um atendimento. Quando os dirigentes de hospitais e os dirigentes públicos dizem se tratar de uma categoria muito grande e, por isso, ser difícil aprovar um piso salarial digno, uma jornada compatível com o trabalho desses profissionais porque a saúde entrará em colapso, na verdade estão negando esses direitos, os quais já estão provados que não afetarão economicamente, ao contrário, trarão mais ganhos para a saúde, com atendimentos mais saudáveis feitos por profissionais mais felizes, realizados, descansados. Negam sim, por terem a certeza do compromisso de cada um desses trabalhadores com a saúde, com a população. Têm a certeza que eles não são irresponsáveis, ao contrário, são comprometidos com a vida, com o outro.

Debater a formação, as funções, as condições de trabalho e os rumos da Enfermagem é, portanto, (re)pensar o Sistema de Saúde. É (re) ver o compromisso com a população e as condições a que são submetidos, diuturnamente, esses profissionais que estão à frente da saúde para os brasileiros. 


\section{Colaboradores}

MCN Silva e MH Machado participaram da concepção e delineamento do estudo, redação e revisão do conteúdo intelectual até a versão final do manuscrito.

\section{Referências}

1. Brasil. Lei no 8.080 de 19 de setembro de 1990. Dispõe sobre as condições para a promoção, proteção e recuperação da saúde, a organização e o funcionamento dos serviços correspondentes e dá outras providências. Diário Oficial da União 1990; 20 set.

2. Santos NR. SUS 30 anos: o início, a caminhada e o rumo. Cien Saude Colet 2018; 23(6):1729-1736.

3. Machado MH, coordenadora. Pesquisa Perfil da Enfermagem no Brasil: Relatório Final. Rio de Janeiro: Nerhus-Daps-Ensp/Fiocruz; 2017.

4. Conselho Federal de Enfermagem (COFEN). Enfermagem em números [página na Internet]. [acessado 2019 Jul 15]. Disponível em: http://www.cofen.gov. br/enfermagem-em-numeros

5. Machado MH, Ximenes Neto FRG. Gestão, da Educação e do Trabalho em Saúde no SUS: trinta anos de avanços e desafios. Cien Saude Colet 2018; 23(6):19711980.

Artigo apresentado em 30/04/2019

Aprovado em 20/08/2019

Versão final apresentada em 20/09/2019 
